\title{
Ward Round - Crocodile bites in Malawi: microbiology and surgical management
}

\section{Biruk L Wamisho1, Jes Bates², Marc Tompkins², Raneem Islam³, Noha Nyamulani², Chistopher Ngulube ${ }^{2}$, Nyengo C Mkandawire ${ }^{1}$}

1. Department of Surgery, College of Medicine, Malawi

2. Department of Surgery, Queen Elizabeth Central Hospital, Malawi

3. Department of Orthopedic Surgery, Brown University, Rhode Island, USA

4. College of Osteopathic Medicine, Michigan State University, Michigan, USA

Corresponding author: Dr. Biruk L Wamisho, College of Medicine, Department of Surgery, Malawi. P.O..Box 122201, Addis Ababa, Ethiopia E-mail: lbiruklw@yahoo.com

\section{Summary}

We present a case series of 5 patients admitted over 5 months to Queen Elizabeth Central Hospital who had sustained injuries from a crocodile bite. Three patients required amputation of a limb. The severe soft tissue injury associated with a crocodile bite and the unusual normal oral flora of the crocodile create challenges in treatment. Progressive tissue destruction and haemolysis are complications of such infected wounds. An antibiotic regime is recommended that covers gram negative rods, anaerobes and may include doxycycline, as well as the need to have a low threshold for early amputation.

\section{Introduction}

Crocodile bites are a relatively common injury amongst people who live in southern Malawi, especially amongst those who live near to the Shire River. The river is a source of fish and drinking water and is used for washing and other domestic activities. Worldwide there are 23 crocodile species but only one, Crocodylus Niloticus (Nile crocodile), is found in the 43 countries of tropical Africa, including Malawi. The Nile crocodile is registered as an endangered species and the size of the crocodile population in Malawi increased significantly after the signing up to the International Convention on Endangered Species (CITES) in 1982. This set a limit on the culling of crocodiles to 200 per year. Malawi subsequently defied this agreement in 2001 due to a significant increase in the number of attacks on people, and up to 800 are now culled annually.

According to a study by Vanwersch carried out at Trinity Hospital (1998), in the Nsanje District of southern Malawi, 60 patients over 4 years were admitted after sustaining crocodile bites $^{1}$. BBC news reports and local statistics stated that two Malawians died each day during the rainy season in 2000, and there were 250 reported bites in the Lower Shire area during $2001^{2}$. The current incidence of crocodile bites is not known ${ }^{3}$.

Crocodiles have a fascinating nature ${ }^{4}$. They exert the most powerful bite of any creature, and once the mouth is closed it is kept closed easily because the mouth-opening muscles are very weak. Crocodilians- alligators, crocodiles, caimans, and their kin- kill hundreds of people each year. While most attacks occur in Africa and Asia, these powerful reptiles are also found in parts of South America, Australia, and the Southern United States. The best way to stay safe in areas where these animals live, is to give them enough space and to exercise caution around water. Local people have developed a variety of different defense strategies to deal with crocodile attacks including poking the eyes or even biting the nose ${ }^{2}$.
Figure 1 A lower limb severely maimed by crocodile

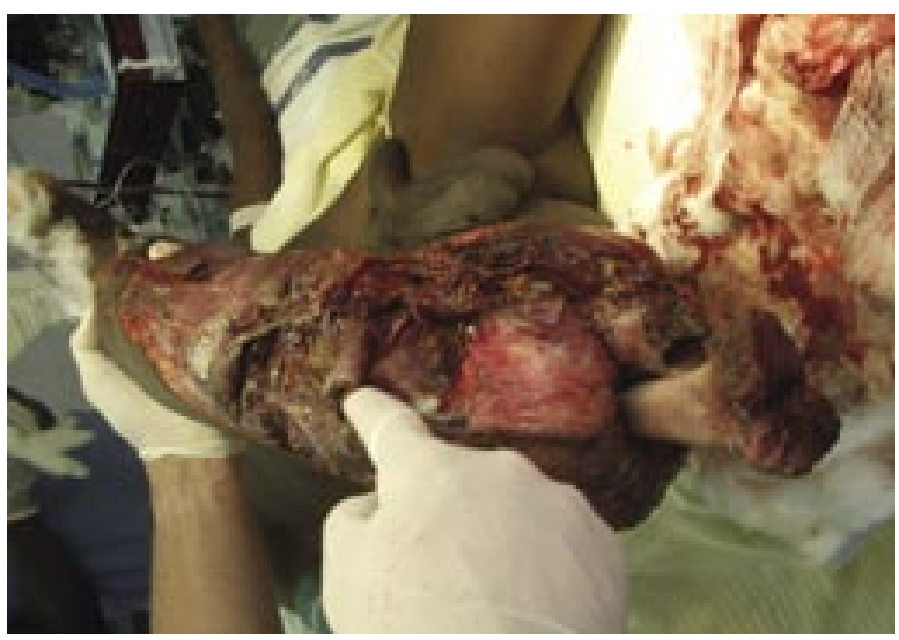

Crocodile bites wounds are usually deep, with severe tissue damage and are frequently contaminated with unusual microorganisms, which are difficult to treat.

In this paper we present 5 consecutive cases of crocodile bites and associated bone or joint injuries that were treated at Queen Elizabeth Central Hospital over a period of 5 months.

\section{Case reports}

\section{Case 1}

A 60 year old man was referred to QECH 48 hours after sustaining a bite to the right leg in the region of the knee whilst fishing. He had been dragged into the water by the crocodile and escaped after poking both eyes with his fingers. On admission he had normal vital signs but was noted to be pale, He had multiple deep puncture wounds in the thigh and calf and around the knee and there was a transverse fracture of the proximal tibial metaphysis. The haemoglobin concentration was $10.3 \mathrm{~g} / \mathrm{dl}$. He was transfused with two units of whole blood and then taken to theatre for debridement where the wound was found to be very contaminated. On a second visit to theatre (after three days) he had a knee bridging external fixator applied. He was given treatment with ceftriaxone and metronidazole. He had 3 further debridements under general anaesthesia, but the wounds continued to suppurate and his haemoglobin concentration dropped to $4.8 \mathrm{~g} / \mathrm{dl}$. During surgery a tourniquet had been applied and there had not been much blood loss. He was mildly jaundiced and liver enzymes were normal, which may indicate haemolysis.. He was tested HIV negative. A wound culture grew Citrobacter species. It was decided to perform an above knee amputation to remove all infected tissue to which the patient readily agreed. In total he received 8 units of blood. After amputation the patient's general condition improved rapidly. He under went secondary closure of the stump after 10 days. At discharge he was mobile on crutches and will return for prosthesis after the stump has matured. 


\section{Case 2}

A 17 year old boy was referred 48 hours after sustaining a bite to the right leg in the region of the knee while swimming. On admission, he was found to have an open distal femoral growth plate fracture with a massive degloving wound around the knee. The foot was cold, pulseless, and insensate and on further exploration in theatre it was found that the popliteal vessels and the tibial and peroneal nerves were all avulsed (Gustilo Grade IIIC, Mangled Extremity Severity (MES) Score 15; A MES score of $>7$ usually indicates an unsalvageable limb). He underwent emergency above knee amputation, and was subsequently given ceftriaxone intravenously. He had a partial secondary closure after 19 days. He received stump care and physiotherapy and was discharged with an appointment for prosthesis fitting.

\section{Case 3}

A 50 year old woman was referred 36 hours after severe bites by two crocodiles, around her right elbow while crossing the river Shire. There was a massive wound just above the elbow with no distal pulse or sensation, and the hand was cold and discoloured, (Gustilo Grade IIIC, MES score 13). Exploration in theatre revealed a totally transected and retracted brachial artery. Median, ulnar, radial and musculocutaneous nerves were all cut. On admission her haemoglobin concentration was $4.9 \mathrm{~g} / \mathrm{dl}$ and she was transfused with 4 units of blood. Emergency above elbow amputation was done and she was given ceftriaxone, metronidazole and doxycycline for 5 days. The stump was healing well when she was discharged one week later.

\section{Case 4}

An 8 year old boy was referred 48 hours post bite with multiple wounds on his thorax, pelvis region and left arm with an open midshaft radius and ulnar fracture. After initial debridement and antibiotic treatment with ceftriaxone the

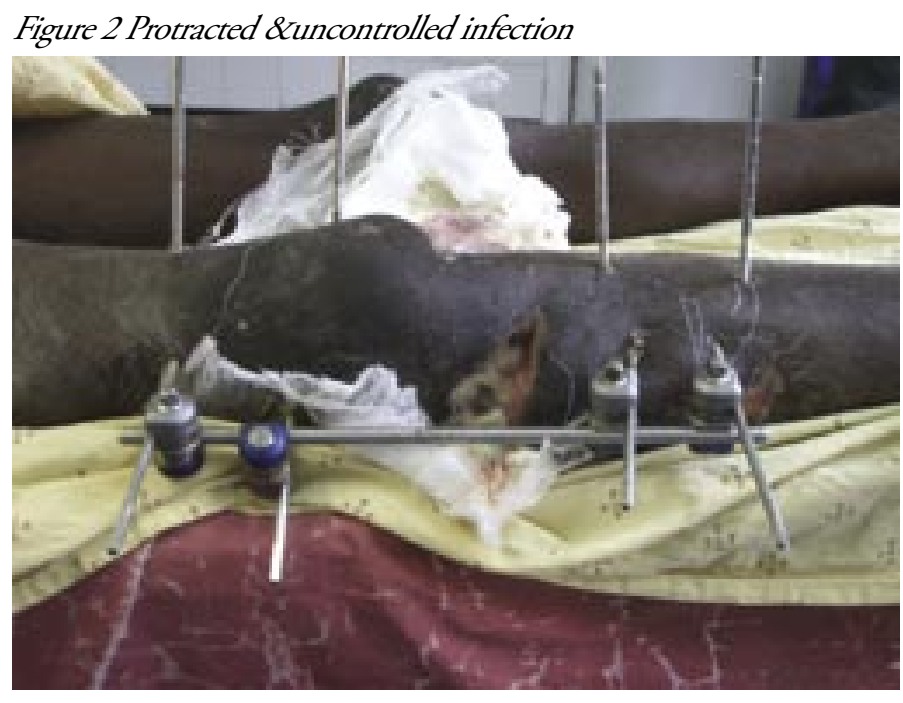

forearm fracture was $\mathrm{K}$ wired and went on to unite without infection. The $\mathrm{K}$ - wires were removed after 6 weeks. The fractures of both bones united well.

\section{Case 5}

A 14 year old boy was referred with a bite to the right leg involving the knee joint. The wounds were debrided and subsequently left to heal by secondary intention without complication. There was no fracture or ligament injury. He was followed up as an outpatient.

All patients received tetanus anti-toxoid.

\section{Discussion}

The management of severe crocodile bites of the limbs is a challenge to the surgeon for two main reasons. Firstly, the bite injury is generally of a crushing and degloving nature with multiple wounds caused by the long rows of teeth. Small superficial puncture wounds can mask significant muscle damage with or without an associated fracture. Secondly,

Table- I. Microorganisms isolated \& reported from Crocodile or alligator bites (References 5-14),

\begin{tabular}{|c|c|c|c|}
\hline Microbe & Classification & Antibiotic of choice $(\dagger)$ & Remarks \\
\hline 1. Vibrio vulnificus & G-ve bacillus & ceftriaxone+ doxycycline & Causes progressive fasciitis \\
\hline $\begin{array}{l}\text { 2. Citrobacter spp. } \\
\text { (C. farmery/C. diversus) }\end{array}$ & G-ve coliform & $\begin{array}{l}\text { macrolides, floroquinolones, } \\
\text { carbapenems }\end{array}$ & Produce B-lactamase \\
\hline $\begin{array}{l}\text { 3. Burkholderia } \\
\text { pseudomallei }\end{array}$ & G-ve aerobic, motile bacillus. & ceftazidime \& doxycycline & \\
\hline 4. Pantoea agglomerans & G-ve aerobic bacillus & $\begin{array}{l}\text { ceftriaxone, gentamycin, } \\
\text { amikacin, meropenem }\end{array}$ & \\
\hline $\begin{array}{l}\text { 5. Bacteroides } \\
\text { melaninogenicus }\end{array}$ & G-ve, anaerobic motile bacillius & $\begin{array}{r}\text { clindamycin, metronidazole, } \\
\text { chloramphenicol }\end{array}$ & Non-spore forming anaerobe \\
\hline 6. Aeromonas hydrophila & $\begin{array}{l}\text { G-ve bacillus facultative } \\
\text { anaerobe }\end{array}$ & $\begin{array}{l}\text { Pyridine carboxylic acids, } \\
\text { chloramphenicol }\end{array}$ & Fatal myonecrosis in immunocopromised \\
\hline 7. Serratia fonticola & G-ve, aerobic & Often multi-resistant & Emerged as human pathogen in 1991 \\
\hline $\begin{array}{l}\text { 8. Clostridium } \\
\text { perfringens }\end{array}$ & $\begin{array}{l}\text { G+ve, anaerobic, spore-forming } \\
\text { bacillus. }\end{array}$ & $\begin{array}{l}\text { Penicillin G, clindamycin, chlo } \\
\text { ramphenicole }\end{array}$ & \\
\hline $\begin{array}{l}\text { 9. Pseudomonas } \\
\text { areogenosa }\end{array}$ & G-ve bacillus & $\begin{array}{l}\text { 3rd gen. cephalosporins, } \\
\text { aminoglycosides, } \\
\text { fluoroquinolones }\end{array}$ & \\
\hline 10. Proteus vulgaris & Aerobic, G-ve bacillus. & ceftriaxone, imipenem & \\
\hline
\end{tabular}

$\dagger$ for empirical treatment; microbiological diagnosis should be attempted to further guide antibiotic choice

G-ve, gram negative; G+ve, gram positive 


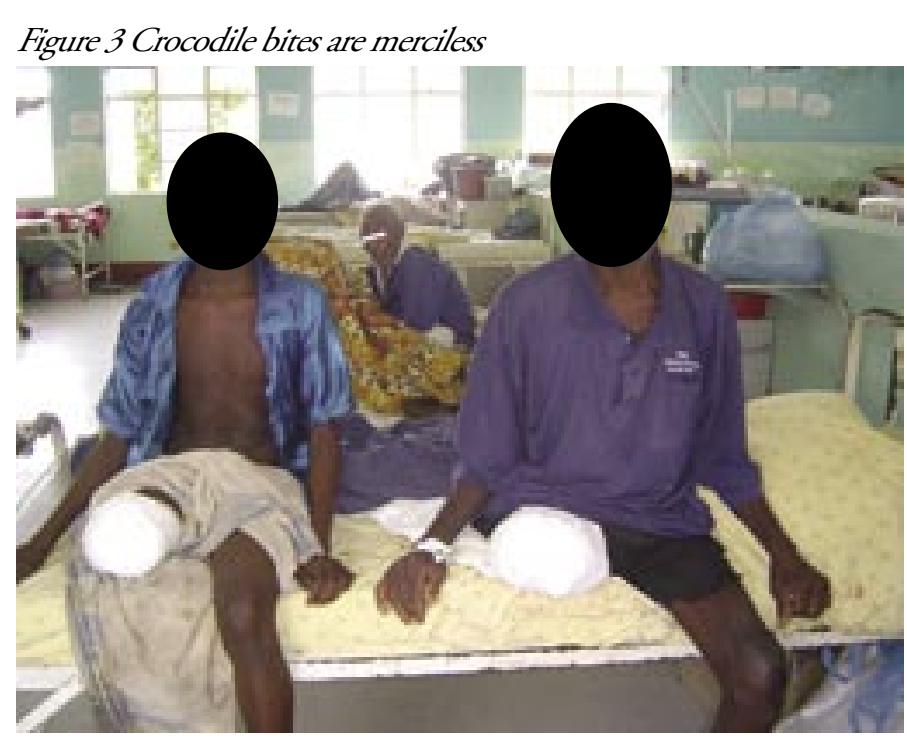

the wounds are contaminated with the normal oral flora of a crocodile which consists of an unusual combination of bacteria as shown in Table 1 . These can cause aggressive local tissue damage, as well as haemolysis. Thirdly, delay in referral often occurs and can contribute importantly to the rate of complications.

Initialmanagementincludes resuscitation, tetanus prophylaxis, empirical broad spectrum antibiotics and wound debridement under general anaesthesia. If an associated fracture is present, the use of an external fixator greatly assists with ongoing wound care. Repeated wound debridements are often necessary to control infection. In case 1 this approach failed to control infection and a subsequent wound culture result showed a multi-resistant Citrobacter species. Due to his rapidly worsening condition and dropping haemoglobin concentration it was decided to amputate the limb.

From Table 1, it can be seen that unusual Gram negative rods and anaerobes, including Clostridia are found as part of the normal flora of the crocodile's mouth or are part of marine flora and therefore may infect crocodile bite wounds. The isolation of one of these organisms does not exclude the presence of other organisms which may be more difficult to isolate. Tetracyclines are first choice agents for Vibrio vulnificus and studies in Taiwan showed a synergistic effect of doxycycline and ceftriaxone. Based on this, we recommend a combination of ceftriaxone, doxycycline and metronidazole $500 \mathrm{mg}$ as empirical treatment, for at least 5 days. Other agents, including carbapenems and aminogycosides may be required in case of unrelenting infections and based on culture results. Rhabdomyolysis has been observed in some patients which may be due to toxic products and enzymes released by the micro-organisms.

\section{Conclusion}

Crocodile bites are a major threat to the Malawian population living around the Shire river. They are a challenging surgical problem, which can be limb and life threatening. The main challenges are related to the severe infections that can occur. Infections are usually polymicrobial, bacteria may be difficult to culture and there may be resistance to common antibiotics. Haemolysis can be associated with ongoing infection, and the haemoglobin should be monitored and the patient transfused as required. From a review of the literature we recommend the use of doxycycline in addition to ceftriaxone and metronidazole as empirical antibiotic treatment. We also suggest a low threshold for amputation in view of the aggressive nature of the infections involved and the frequently present severe degree of tissue necrosis; this may be a life saving procedure.

\section{References}

1. Vanwersch K; Crocodile bite injury in southern Malawi: Trop Doct. 1998 Oct; 28(4):221-2.

2. http://news.bbc.co.uk/2/hi/africa/592352.stm

3. http://www.afrol.com/Categories/Environment/env053_crocos_ malawi.htm

4. http://www.hitsgarden.com/14-amazing-facts-about-crocodiles/

5. Caldecott D. G et al; Crocodile attack in Australia: an analysis of its incidence and review of the pathology and management of crocodilian attacks in general: Wilderness Environ Med. 2005 Fall;16(3):143-59

6. Harding BE, Wolf BC; Alligator attacks in southwest Florida. J Forensic Sci. 2006 May; 51(3):674-7.

7. Auerbach PS; J. Hazardous marine animals. Emerg Med Clin North Am. 1984 Aug; 2(3):531-44.

8. Noonburg G.E;Management of extremity trauma and related infections occurring in the aquatic environment. J Am Acad Orthop Surg. 2005 Jul-Aug; 13(4):243-53.

9. Goldstein EJ;Infectious complications and therapy of bite wounds. J Am Podiatr Med Assoc. 1989 Oct;79(10):486-91

10. Tsai Y.H et al; Necrotizing soft-tissue infections and sepsis caused by Vibrio vulnificus compared with those caused by Aeromonas species. J Bone Joint Surg Am. 2007 Mar; 89(3):631-6.

11. Marta E. G et al; Isolation of Serratia fonticola from skin lesions in a Nile crocodile (Crocodylus niloticus) with an associated septicaemia. The Veterinary Journal Volume 176, Issue 2, May 2008, Pages 254256

12. Microorganisms isolated from different animal bites: http://emedicine. medscape.com/article/768875-overview.

13. Johns Hopkins Hospital online antibiotic guide; http://prod.hopkinsabxguide.org

14. John D Urschel ;Necrotizing soft tissue infections Postgrad Med J 1999;75:645-649 (November) 